\title{
Mitigation of Risk and Associated Complications of Diagnostic Amniocentesis during Second Trimester of Pregnancy (15-22 Weeks)
}

\author{
Nahar $\mathrm{N}^{1}$, Chowdhury $\mathrm{L}^{2}$, Akter $\mathrm{MR}^{3}$ \\ DOI: https://doi.org/10.3329/jafmc.v16i1.53841
}

\begin{abstract}
Introduction: Amniocentesis is a procedure in which amniotic fluid is collected from the amniotic cavity for testing or treatment. Amniotic fluid is the fluid that surrounds and protects a baby during pregnancy. Amniotic fluid contains fetal cells and various proteins and provides valuable information about baby's health.
\end{abstract}

Aim: To evaluate the risk and associated complications during diagnostic amniocentesis.

Methods: This prospective study was conducted by performing amniocentesis among pregnant ladies of early second trimester at Dhaka CMH, and Aklima General Hospital Limited, Mirpur, Dhaka from July 2016 to June 2019. A total of 50 patients were selected by age of the patient, history of previous pregnancy outcome, parental haemoglobinopathy and few other factors triggered these cases to be put under this study.

Results: No major complications have been observed during and after the procedure because of appropriate pre-operative and post-operative management.

Conclusion: There are some common and known risks which are associated with amniocentesis like miscarriage, amnionitis, fetal trauma etc. Through skilled execution with the help of real-time ultrasound guidance and proper pre-operative and post-operative care, we can avoid complications and get benefit from amniocentesis.

Key-words: Amniocentesis, Second Trimester of Pregnancy, Complications, Amniotic fluid.

\section{Introduction}

Amniocentesis means the extraction of amniotic fluid through a mother's abdominal walls and is the most commonly used method for detecting chromosomal abnormalities ${ }^{1}$. This procedure is usually performed between the 15th and 20th week of pregnancy and early measures can lead to less success, increased unsuccessful cell culture, higher risk, and fetal complications ${ }^{2}$. Amniocentesis is the first invasive procedure used in fetal medicine for both prenatal diagnosis and therapy. Amniotic fluid withdrawal has been practiced for more than 150 years. The transabdominal evacuative amniocentesis was repored by Schatz $\mathrm{VF}^{3}$ in 1882 describing release of amniotic fluid from a patient with polyhydramnios. Menees et a ${ }^{4}$ reported removal of amniotic fluid by transabdominal needling using a radio- opaque contrast to outline the fetus and placenta in 1930.
At the beginning of the $1950 \mathrm{~s}^{5}$, it was used to determine the amniotic composition in cases of Rhesus iso- immunization and to correlate it with the severity of the condition of the newborn. Later on, Liley ${ }^{6}$ published the well-known correlation between the deviation of the spectral absorption curve of amniotic fluid resulting from bilirubin and the severity of rhesus iso-immunization. Since Liley's studies, the practice of amniocentesis in pregnancies complicated by Rhesus disease was the standard procedure in obstetric practice until Mary described the use of middle cerebral artery (MCA) peak velocity in predicting fetal anemia and the need for in-utero blood transfusion in a noninvasive way.

Amniocentesis was used for diagnostic reasons in the '50s, as a method for sex determination by the identification of Barr bodies in the non-cultured amniocytes ${ }^{7}$. About 10 years later, Steele and Breg reported in their paper in Lancet that the karyotype of the embryo was determined through an amniotic fluid cell culture ${ }^{8}$. During the same year Creasman WT $^{9}$ et al published similar findings later. The first case of prenatal diagnosis of Trisomy 21 (Down syndrome) was reported by Hsia DY-Y et a ${ }^{10}$. In 1970, Nadler and Gerbie ${ }^{11}$ published the 'Role of amniocentesis in the intrauterine diagnosis of genetic defects' in the New England Journal of Medicine. This article was an innovation concerning genetic amniocentesis and diagnosis and since then genetic laboratories for analysis of amniotic fluid had become prevalent and indications for genetic amniocentesis included the detection of chromosomal abnormalities, gene disorders, X-linked conditions, inborn errors of metabolism, and the neural tube defects.

Amniocentesis has been established as a basic invasive method for the prenatal diagnosis of various pregnancy related conditions, such as fetal karyotyping, diagnosis of metabolic or enzymatic diseases, assessment of the severity hemolytic disease, establishment of lung maturity, diagnosis of fetal infections. Additionally, amniocentesis is used for the infusion of various drugs into the amniotic cavity, determination of the composition of the amniotic fluid and finally for evacuation of hydramnion.

\section{Materials and Methods}

This prospective study was conducted by performing amniocentesis among 50 pregnant ladies of early second trimester at Dhaka $\mathrm{CMH}$ and Aklima General Hospital Limited from July 2016 to June 2019. The study was conducted by following specific steps:

1. Lt Col Nargis Nahar, MBBS, FCPS, DGO, MCPS, Fellowship in Fetomaternal Medicine and High Risk Pregnancy, Associate Professor of Obstetrics \& Gynaecology, Armed Forces Medical College, Dhaka (E-mail: drnargisnahar100996@gmail.com) 2. Brig Gen Liza Chowdhury, MBBS, FCPS, MCPS, Advisor Specialist \& Head of the Department of Obstetrics \& Gynaecology, Combined Military Hospital, Dhaka 3. Lt Col Mst Ralifa Akter, MBBS, DGO, FCPS, Assocaite Professor of Gynaecology, Armed Forces Medical College, Dhaka. 
Selection of patient for diagnostic amniocentesis: Amniocentesis is not required for all the pregnant ladies rather some specific selection criteria guide us to select a patient for amniocentesis. In this study amniocentesis was performed on 50 patients where their age group varies from 20 to 42 years. Among them, 10 cases were done for fetal karyotyping as their age group was more than 35 years old and/or they had history of previous baby with Down syndrome, 5 cases for diagnosis of prenatal muscular dystrophy as their previous babies were diagnosed as case of muscular dystrophy, 5 cases for diagnosis of prenatal spinal muscular atrophy because they had family history of same disease and history of consanguineous marriage, in 5 cases previous babies had multiple congenital anomaly and rest 25 cases were done for diagnosis of fetal haemoglobin because both father and mother had haemolytic disease.

Pre-operative procedures: After selection of above 50 cases, we had gone through following pre-operative procedure for all the cases-

(i) Counseling on risk and complication of the procedure

(ii) Informed written consent from the patient

(iii) Administration of proper pre-operative drugs (antibiotics \& uterine sedative)

(iv) Maintenance of proper asepsis of patient, specialist and assistant

(v) Draping of the patient before execution of amniocentesis

Proper execution of amniocentesis and sample handling: All the selected cases had gone under amniocentesis after completion of pre-operative formalities. Amniocentesis was performed under real-time 2D ultrasound guidance as an outdoor procedure. At first 22 gauges spinal needle was inserted inside amniotic cavity and a $20 \mathrm{cc}$ syringe was used to draw around $20 \mathrm{cc}$ of amniotic fluid (sample) for analysis. The sample was handed over to respective representative of genetic laboratory immediate after the collection or the sample was preserved at certain temperature according to their guidance.

Meticulous post-operative management: After the procedure, all the patients were kept in rest for 1-2 hours in the hospital and then were been permitted to go back home and advised for two weeks of rest where heavy works, journey and sexual intercourse were not allowed except regular light house hold works. Patients were also advised to complete the medicine courses according to prescription.

Report analysis and patient follow-up: Usually it takes two weeks to get genetic report and patients were advised for a follow-up visit with their reports. At this follow-up visit, their complaints were noted which were suspected to be triggered from amniocentesis procedure. These complains were treated as complications and further data analysis has been performed accordingly to conclude the result.

\section{Results}

According to their complaints at follow-up visits till delivery all the 50 patients delivered healthy baby and no fetal loss was observed. Pricking pain was a common complain during the insertion of needle at the time of amniocentesis but that pain was subsided automatically after the procedure. Pricking pain is a normal phenomenon for any person undergoes this procedure. In one case, collected amniotic fluid was found mixed with very small amount of blood because an injury was made due to anterior location of placenta. That particular sample was discarded and on the same sitting another insertion was made avoiding placenta and that was successful. One case was reported with less amount of cell to analyze and the geneticist requested for second sample. That case was performed before 15 weeks pregnancy. After completion of 17 weeks, amniocentesis was repeated for proper analysis and that was successful. Faced incidents are summarized according to our selection criteria in Table-I.

Table-I: Incidents faced during Amniocentesis $(n=50)$

\begin{tabular}{|l|c|c|c|c|c|c|c|}
\hline \multicolumn{2}{|c|}{ Incidents Faced } & \multicolumn{6}{c|}{ Probable Risks \& Associated Complications } \\
\hline Selection Criteria & $\begin{array}{c}\text { Number of } \\
\text { Patient }\end{array}$ & $\begin{array}{c}\text { Fetal } \\
\text { Loss }\end{array}$ & $\begin{array}{c}\text { Preterm } \\
\text { Delivery }\end{array}$ & $\begin{array}{c}\text { Fetal } \\
\text { Trauma }\end{array}$ & $\begin{array}{c}\text { Pricking } \\
\text { Pain }\end{array}$ & $\begin{array}{c}\text { Blood Mixed } \\
\text { Amniotic Fluid }\end{array}$ & $\begin{array}{c}\text { Repetition of } \\
\text { Procedure }\end{array}$ \\
\hline Fetal Karyotyping & 10 & 0 & 0 & 0 & 10 & 0 & 0 \\
\hline Muscular Dystrophy & 5 & 0 & 0 & 0 & 5 & 0 & 0 \\
\hline Spinal Muscular Atrophy & 5 & 0 & 0 & 0 & 5 & 0 & 0 \\
\hline Multiple Congenital Anomaly & 5 & 0 & 0 & 0 & 5 & 0 & 0 \\
\hline Fetal Haemoglobin Type & 25 & 0 & 0 & 0 & 25 & 1 & 1 \\
\hline \multicolumn{1}{|c|}{ Total } & $\mathbf{5 0}$ & $\mathbf{0}$ & $\mathbf{0}$ & $\mathbf{0}$ & $\mathbf{5 0}$ & $\mathbf{1}$ & $\mathbf{1}$ \\
\hline
\end{tabular}

These collected amniotic fluids of 50 patients were undergone through genetic testing and the results are summarized in following Table-II.

Table-II: Genetic test results $(\mathrm{n}=50)$

\begin{tabular}{|l|c|c|l|}
\hline Selection Criteria & $\begin{array}{c}\text { Number } \\
\text { of Patient }\end{array}$ & $\begin{array}{c}\text { MCC(Maternal Cell } \\
\text { Contamination) }\end{array}$ & DNA Report \\
\hline Fetal Karyotyping & 10 & Negative & Normal Karyotype \\
\hline Muscular Dystrophy & 5 & Negative & No mutation of DMD Gene \\
\hline Spinal Muscular Atrophy & 5 & Negative & No deletion/ duplication in SMN1/ SMN2 Gene \\
\hline Multiple Congenital Anomaly & 5 & Negative & No deletion/ duplication of chromosome \\
\hline Fetal Haemoglobin Type & 25 & Negative & Heterozygous types 2 cases, no pathogenic variants 23 cases \\
\hline
\end{tabular}




\section{Discussion}

During amniocentesis, the feto-maternal unit is injured and thus a number of complications may occur. Maternal complications are rare. They include perforation of the intra-abdominal viscera with subsequent intra-abdominal infection, sepsis, bleeding, blood group sensitization and uterine contractions ${ }^{12}$. The use of ultrasound guidance during amniocentesis has minimized the risk of maternal injury. Also aseptic technique and the use of anti-D immunoglobulin have eliminated the risk of maternal sepsis and rhesus sensitization. Fetal complications are the main concern. They include fetal loss, placental abruption, preterm labor and preterm rupture of membranes. Needle puncture injuries of the fetus and injury due to withdrawal of amniotic fluid (e.g. amniotic bands) are rare especially since amniocentesis is being performed under ultrasound guidance. Amniocentesis may also cause intra-amniotic infections through the introduction of microorganisms into the amniotic cavity via the needle. In order to eliminate the possibility of an infectious complication, rules of asepsis procedures which apply in all surgical procedures must be applied during amniocentesis, such as the aseptic cleaning of the skin and using sterilized medical gloves and needles. However, endometrial infections are not always related to amniocentesis but may exist before the prenatal intervention ${ }^{13,14}$.

Fetal loss is the ultimate risk of genetic amniocentesis. When amniocentesis was first introduced in the clinical practice the risk of miscarriage due to the procedure could not be estimated accurately because there was lack of ultrasound guidance and lack of determination of fetal viability before the procedure and also skilled feto-maternal specialist was rare. Since fetal miscarriage does not occur only in association with amniocentesis, the background loss rate which is associated with the gestation age, parity and any other underlying risk factors is important to be determined before estimating the procedure loss rate. For instance gestational age at the procedure is an important determinant of the observed fetal loss rate, since the earlier the pregnancy the greater is the pre-procedure risk of miscarriage.

The risk of fetal loss after amniocentesis has been evaluated by several series from single centers and a number of multicenter studies. The controversial results of these studies merely imply the difficulties in evaluating the procedure related loss rate and the changes in practice of the procedure. In these cases of 50 pregnant ladies, skilled handling helped us to avoid the risk of fetal loss and all the patients delivered healthy babies.

The association of second trimester amniocentesis and delivery before 37 weeks was evaluated by a case control study in 2003 by the EUROPOP Group ${ }^{15}$. Three thousand and ninety-one preterm births and 5,298 controls randomly selected from singleton births born at term during 1994 to 1997 were analyzed. An increased risk of preterm delivery was found in women having second trimester genetic amniocentesis after taking into account other risk factors and confounding variables (odds ratios OR 1:59, 95\% confidence intervals (95\% Cl): 1.31-1.92). The association was statistically significant and similar for spontaneous preterm delivery and induced preterm delivery. On the contrary, other studies ${ }^{16,17}$ have shown no difference in the rate of preterm delivery after amniocentesis. In this study, no such incident was observed. Theoretically, the risk of direct fetal needle injury should be reduced with the use of simultaneous ultrasound guidance. Nevertheless several case reports document or describe cases of fetal injury to the amniocentesis needle, despite the use of simultaneous guidance for the procedure. This association though is not based on direct evidence. In addition, there are reports of fetal skin marks in cases without amniocentesis and these suggest that these marks may not be the result of needle puncture of the fetus ${ }^{18}$. In this study, no such incidents were present.

Feto-maternal hemorrhage occurs in approximately $50 \%$ of all women $^{19}$ and during amniocentesis on one out of $\mathrm{six}^{20}$. The attributed risk is $1 \%$ greater than the background risk of $1.5 \%{ }^{21}$. As for preventing the Rhesus sensitization of the mother and when the husband is Rhesus positive, every Rhesus negative mother must be given $300 \mu \mathrm{g}$ anti-D.

Immunoglobulin after amniocentesis, provided of course the indirect Coombs is negative ${ }^{22,23}$. Other means to minimize the risk is the use of small gauge needles and to avoid transplacental approach. In the same way, HIV and hepatitis virus positive pregnant women are safe to undergo amniocentesis provided that viral load of patients is low and the transplacental route is avoided ${ }^{24}$. The use of real time ultrasound guidance during the procedure helps the feto-maternal specialist to avoid the transplacental route which is crucial in cases of Rhesus negative mothers and HIV or hepatitis virus positive pregnant women. No such transmission was reported to any baby as all the cases were concluded through successful outcome.

\section{Conclusion}

From this study we can conclude that by following proper pre-operational procedures a skilled feto-maternal specialist can perform flawless amniocentesis of pregnant ladies of second trimester with the help of real-time ultrasound guidance followed by appropriate post- operative care and can guide the patient towards successful outcome through follow-up visits and necessary management.

\section{References}

1. Rapp R. Testing women, testing the fetus: The social impact of amniocentesis in America. Routledge; 2004.

2. Enzensberger $\mathrm{C}$, Pulvermacher $\mathrm{C}$, Degenhardt J et al. Fetal loss rate and associated risk factors after amniocentesis, chorionic villus sampling and fetal blood sampling. Ultraschall Med 2012; 33(7):75-9.

3. Schatz VF. Gine besondere art von einseitiger polyhydramnie mit anderseitiger oligohydramnie bie eineiigen zwillingen. Arch Gynaecol 1882; 19:329. 
4. Menees T, Millar JD, Holly LE. Amniography. Preliminary report. Am J Roentgenol 1930; 24:353-66.

5. Bevis DCA. The composition of liquor amnii in haemolytic disease of the newborn. J ObstetGynaecol Br Emp 1953; 60:244-51.

6. Liley AW. Liquor amnii analysis in management of pregnancy complicated by rhesus sensitization. Am J Obstet Gynecol 1961; 82:1359-70.

7. Fuchs F, Riis P. Antenatal sex determination. Nature 1956; 177:330.

8. Steele MW, Breg WR. Chromosome analysis of human amniotic fluid cells. Lancet 1966; 1:383.

9. Creasman WT, Lawrence RA, Thiede HA. Fetal complications of amniocentesis. Br J Obstet Gynaecol 1981; 88(11):1081-5.

10. Hsia DY-Y, Nadler HL Shih L (1968) Biochemical changes in chromosomal abnormalities. Ann NY Acad Sci 171:526-36.

11. Nadler HL, Gerbie AB. Role of amniocentesis in the intrauterine detection of genetic disorders. N Engl J Med 1970; 88(11):1081-5.

12. National Institute of Child Health and Human Development National Registry for amniocentesis study group: Mid trimester amniocentesis for prenatal diagnosis: Safety and accuracy. J Am Med Assoc 1976; 236:1471.

13. Cassell GH, Davis RO, Waiter KB, et al. Isolation of mycoplasma hominis and ureaplasma urealyticum from amniotic fluid at 16-20 weeks of gestation: Potential effect on outcome of pregnancy. Sex Transm Dis 1983; 10:294.

14. Gray DJ, Robinson H, Malone J, et al. Adverse outcome in pregnancy following amniotic fluid isolation of ureaplasma urealyticum. Prenat Diagn 1992; 12:111-7.
15. Medda E, Donati S, Spinelli A, Di Renzo GC. Europop group genetic amniocentesis: A risk factor for preterm delivery? Eu J Obstetr and Gynecol Reprod Biol 2003; 110:153-8.

16. Tabor A, Philip J, Madsen $M$ et al. Randomised controlled trial of genetic amniocentesis in 4606 low-risk women. Lancet 1986; 1:1287-93.

17. Tongsong T, Wanapirak C, Sirivatanapa $P$ et al. Amniocentesis-related fetal loss: A cohort study. ObstetGynecol 1998; 92(1):64-7.

18. An assessment of the hazards of amniocentesis: Report of the MRC working party on amniocentesis. BJOG 1978; 85(suppl):1-41.

19. Clayton EM, Feldhaus WD, Whitacre FE. Fetal erythrosytes in maternal circulation of pregnant women. Obstet Gynecol 1964; 23:915-19

20. A Tabor, J Bang, B Norgaard-Pedersem. Fetomaternal haemorrhage associated with genetic amniocentesis: Results of a randomized trial. $\mathrm{Br} \mathrm{J}$ Obstet Gynecol 1987; 94:528-35.

21. Murray JC, Karp LE, Williamson RA et al. Rh isoimmunization related to amniocentesis. Am Journal of Medical Genetics 1983; 16:527-34.

22. American College of Obstetricians and Gynecologists: Prevention of D Isoimmunization. ACOG Tech Bull No. 147, 1990.

23. WHO. Prevention of rhesus sensitization. Who Technical Report Series 1971, №. 468.

24. Maiques V, Garcia-Tejedor A, Perales A et al. HIV detection in amniotic fluid samples amniocentesis can be performed in HIV pregnant women? Eur J Obstet Gynecol Reprod Biol 2003; 108:137-41. 